\title{
Research on the Influencing Factors of the Career Planning of Graduate Student Education in the New Era
}

\author{
Bo $\mathrm{Li}^{1, \text { a }}$ \\ ${ }^{1}$ Jilin Agricultural University, Graduate School, Changchun130118, China \\ a 83574736@qq.com
}

Keywords: new era, graduate career planning education, influencing factors

\begin{abstract}
Graduate students are in a critical period of life transition, the objective requirements of this group in the formulation and modification of career planning should be more prudent to grasp the factors that influence the good career planning, in order to ensure the formulation of career planning with reasonable positioning, correct path and operation process, then reach the target " person-job fit”.
\end{abstract}

\section{Introduction}

Just stepped out school most graduate students facing determined, home, career and other pressing issues, which in career most pressing. A long-term follow-up study at Harvard University shows that career success is hard to achieve without a clear goal. In fact, only $4 \%$ of people succeed in the end. The reason could be achieved successful common characteristic is that them early for her to do career planning, and always adhere to. Thus, the importance of career planning education is beyond doubt.

At present, all kinds of institutions or institutions to carry out the career planning education mainly for undergraduate students, and graduate students are often ignored. At the same time, the graduate students' employment satisfaction is low, and the occupation career planning is absent. Graduate students career planning is important and urgent, but not in the formulation and modification of career planning "in an emergency and chaos", good grasp of cognition, strategies and methods of the three basic elements to effective arrangement development of career and life goals.

\section{The Cognitive Factors of Graduate Career Planning}

North Will, a famous management scientist, defined career planning: the direction, time and plan of action that the individual combined with their own situation and the immediate constraints to achieve their career goals. How to determine the future direction of action, time and program before the combination of its own situation and constraints? This requires graduate students in the development of career planning with a basic element: a good cognitive. And this is usually reflected in the multiple cognitive perspective, the correct values and a clear understanding of the three aspects of the cognitive.

Multiple Cognitive Perspective.Some graduate students suggest that several important conditions to determine their future occupation career, and will focus on the occupation career planning on how to create some favorable conditions or inhibition of several adverse conditions, in order to achieve the effect; some graduate students think their occupation career development is the nature of the "car to the Piedmont Road," each stage of processing good occupation development on the line, do not make a long-term plan; some graduate students think their occupation career planning is very easy to do, learning has made some pioneer occupation path is a good example of it; and some graduate students think they have a very clear objectives. Occupation career planning is not a problem, want to get things done around" my end is no regrets "to be. The above ideas reflect the graduate students face of career planning held by different types of cognitive perspective, should be ideal to see, for different situations of students' cognitive perspective has different preference, but they are not necessarily exclusive and exclusive, and there is no absolute superiority, 
many different choices lead to different cognitive perspectives finally is "similar".

Correct Values. The current our country graduate students generally exist too much emphasis on market supply and demand and neglect to fulfill the mission of university academic, too much emphasis on to catch up with the trend of the employment and ignore the individual self-development, too much emphasis on after graduation of and wage income contempt after graduation, such as the ability to enhance, the large degree is graduate to a reasonable career planning values have not. Research to develop career planning when students should realize professional, work, job and career is several different but related concept, if not a correct understanding of their current professional or is the value of the research in the field of, can not be a correct understanding of the value of the future choice of profession, it will seriously affect the research phase of time and resource allocation, and the current study and future career, career of efficient convergence.

A Clear Cognitive Schema.Graduate students in the development of career planning, clear career planning cognitive schema also includes contents are as follows: summarized in the review of professional type icon in the clear, clear self- resource icons and clear the social environment of cognitive schema. They are "what are the career planners" to do?" What resources are there?" "In what background?" Problems.

First of all, it is the key to career planning to construct a clear professional type of self, as the basis of career development. Foreign scholars have long recognized that John Holland is therefore summarize six vocational aptitude (type): practical aptitude; aptitude research; social aptitude; conventional aptitude; enterprise aptitude; artistic aptitudes. His research shows that every kind of career orientation for a specific number of career and personal career orientation can be determined by means of a series of tests. Secondly, the construction of a clear self-resource summary of the general requirements from the individual human resources, economic resources and social resources of the three dimensions of a comprehensive consideration. Resources are determined by capital, and capital is the basis of competitive ability. Graduate students in the development of career planning, in particular, can not be ignored to play their own human resources, can not ignore the construction of a good social resources.

\section{Strategic Elements of Graduate Career Planning}

American scholar Swain that a specification of the career planning should include: personal traits of clarification and understanding, education and career information and personal relationship with the environment coordination. These three aspects are equally important in career planning. how in the three aspects of the limited time and resources in the allocation of choice to make outstanding career planning program? This involves the strategy of graduate career planning. On the basis of the cognitive factors of graduate career planning, strategy is another factor that must be considered.

To Emulate Strategy. Scholars have said that it is not to say graduate enrollment increased graduate employment pressure, it is better to say that the decline in the quality of postgraduate enrollment is an important factor in the cause of severe employment. Indeed, the single is employment orientation of students career planning can not fail to take into account such a fact: outstanding ability and political integrity of students in career route than those not good enough research to flow more smoothly. Graduate students in the process of making career planning, see Yin Si Qi to choose some good example for reference or imitation of the object is a feasible strategy. In the graduate students of the same age group, in terms of academic research, social practice, knowledge application,, in groups to graduate students, to go abroad for further study, domestic entrepreneurship, well-known enterprise employment, supporting grassroots development, carry forward the social morals and so on in, to make an example of excellence, these are graduate students in the development of career planning for the reference object.

Seeking Truth from Facts. Graduate students in the development of occupation career planning should be realistic and timely. According to local conditions, the students should see their own personality traits, resource elements and development stages, combined with their own dominant value orientation, to develop their own career planning for the current situation. The 
requirements of students career planning must be decomposed into several stages of short-term, medium-term and long-term, and divided into different time period to complete. If there is no clear time, will make career planning in empty talk and failure. Different people have different longitudinal strategy, as Massachusetts science industry and trade of the Sloan School of management professor grace, with a person to oneself more and more understanding, the person will be more and more obviously formation a accounted for dominant career anchors .Career anchor is a career line or the leading value trend, is when a person had to make a choice, however, does not give up the principle of things, is surrounded by people of career choice and development center. Mercy based on its for the MIT and MIT Sloan School of management graduate of case study, and puts forward the technical function career anchor type, safe and stable type of career anchor, management authority career anchor, innovation type of career anchor, independent type of career anchor and so on five basic career anchor.

Horizontal Tolerance Strategy. A good career planning is not achieved overnight, is constantly absorbing new information, new ideas, new knowledge and skills based on the formation of the. The role of the individual cluster has limitations, which determines the Those closely involved cannot see clearly. is difficult to avoid the A bystander is always clear-minded. ". Before establishing or modifying the career planning, graduate should be more from various academic forums, academic salons, social activities draw comprehensive information to support their own career planning, should be carefully from the society, cities, campuses, research institutes, laboratories and other field found their career concept is correct or not, humbly from around the students, teachers, friends and where is center of a variety of career planning and career development guidance and other institutions to seek career planning advice.

Innovation. Only a firm goal, and in accordance with the changes in the situation in a timely manner to adjust their plans, it is possible to achieve the desire to succeed. But the firm is not fully adhere to the development of the profession should not stick to the existing career planning. Graduate career planning on the one hand, starting from the previous learning stage (undergraduate, junior college or other), on the one hand to undertake after the career development stage, and at the same time based on the graduate level. Both graduate student period, the annual or monthly reflection or by applying mutatis mutandis before learning stage expected with reference to later stage of social requirements, has been developed to get rid of the assessment of career planning is an important strategy. The strategies of graduate career planning assessment usually include self -expectation assessment, social comparison evaluation, third party evaluation and so on.

\section{Methods of Graduate Career Planning}

The third basic factors that should be met in the graduate career planning are the key elements of the research career planning. When you know why career planning and know what direction to plan career, what kind of career planning method has become a problem must be considered. To make a good career planning, we must combine the cognitive ability and the existing resources, select the appropriate planning methods.

Components of the Method. The method of career planning includes the method of collecting the information of the planning, the method of integrating the resources of the planning and the method of making the planning process. Graduate students need to be classified in their career planning. Planning information is derived from a clear cognitive schema of career planning, and the specific methods of collecting planning information are also found in how to effectively clarify the cognitive schema. The specific method of resource integration planning possible sources in the field of strategic management of SWOT matrix analysis method, or is derived from the opportunity cost of economics analysis, from theory of social systems AGIL mode analysis method. The method of implementing the planning step is usually based on the summary of existing cases. A commonly used method is a six step: self-assessment, assessment of career opportunities, determine career goals, career development path selection, make career action plan and measures, evaluation and feedback. PPDF (personal performance development file) is also a common career planning method, this method through the integration of personal situation, now and the future development of three 
sections existing resources in order to develop planning process.

Basic Meaning of Method Elements. Methods elements are the basic elements of the graduate career planning before the implementation of the two basic elements. Regardless of cognitive how vision or strategy how to operate from a strategically advantageous position, if there is no specific methods for practical support can not play a big role. Usually case, study and formulate career planning, only the existing human resources, economic resources, social resources were summarizes in detail, after careful analysis of each choice action advantages, weaknesses, opportunities and threats, career planning in each a choice to be made to planning step by step down. Method elements are more easy to learn from each other than the first two basic elements of graduate career planning, because the spread of modern information is very convenient, and career planning technology has been a lot of models. But it must be realized that it is easy to get the common method which can not be easily collected and borrowed. The common method is often difficult to solve the development needs of personality. Graduate students in the development of career planning, should be fully grasp or clarify the cognitive, strategic elements based on the analysis and selection of specific methods.

\section{Reference}

[1] Jiang Rongtao. College student occupation career planning and training pattern reform of higher education on Xiangtan [J].Journal of University, 2004 (3), 139

[2] college students career development and employment guidance curriculum teaching requirements [Z]. Department of Education Office, 2007,12

[3] Zhao Qiong, a Liangtie. On the difference of the occupation career planning [J]. Economic Forum, 2005 (13), 99

[4] Li Jun. Survey and analysis of the value orientation and career planning of college students career planning [J]. Journal of Hefei University (Social Science and society, 2007 (1), 115- 118

[5] Zheng Xiangjiang, Hao Shengyue. Graduate survey and influencing factors analysis of the occupation career planning status [J]. China high Teaching research, 2008 (4), 55

[6] Qiu Meihua, Dong Huaxin. Career development and guidance [M]. Beijing: Psychology press, 1997,2

[7] Li Baoyuan. Modern organization learning human resources development [M]. Beijing: Economic Science Press, 2005,3

[8] Xu Minhua. Problems and solutions of career planning education for master's degree students [J]. career development education, 2013,4 